\title{
Single Axis Solar Tracking System
}

\author{
Ei Ei Aung \\ Department of Electronic \\ Engineering \\ Technological University (Lashio), \\ Myanmar
}

\begin{abstract}
This paper describes the analysis and implementation of solar tracking system to generate electricity from renewable energy. This is aim to recover the demand on electricity in the rural area. To get maximum energy, solar panel is tracked the path of sun using Arduino Uno, LDR sensors, stepper motor and solar panel. And the battery is used to store the energy from the solar panel through the charge controller and applied to the intended loads. Data analyzing is accomplished and compared to sunny day and cloudy on hour to hour.
\end{abstract}

Keywords: solar; tracking; Arduino Uno; LDR; stepper motor; charge controller, analysis

\section{INTRODUCTION}

In this day, renewable resource is one of the major concerns because of increasing more power demand but the quality and availability of conventional energy sources are not enough.Energy is essential factor for the development of any nations of all over the world. Most of the energy production depends on fossil fuel. The resources of the fossil fuels are limited, so that there are growing demand for energy from renewable resources like solar, geothermal and ocean tidal wave. Among all renewable systems, photovoltaic system is the one which has great chance to replace the conventional energy resources. To enhance the performance of solar panel the only way is to increase the intensity of light falling on it. Solar tracker is the best technology to increase the efficiency of solar panel by keeping panel aligned with the suns position. The advantage of using solar power for small power generation is its probability; it can be carried whenever or wherever small power generation is required.

In this research, a microcontroller based simple and easily programmed automatic solar tracker is presented. Design and construction of a prototype for solar tracking system detected the sunlight using Light dependent Resistors (LDR), is discussed in this work. The control circuit for the solar tracking system is based on Aurdino Uno. This is programmed to detect the sunlight through the LDRs and then actuate the stepper motor to position the solar panel where it receives maximum sunlight. Compared with any other type of motor, the stepper motor is more controllable, more energy efficient, more steady and having high tracking accuracy and suffering little environmental effect.

In this paper, there are mainly five sections to implement this control system. Firstly the system is introduced. The second section describes the system description of overall control system, and some detailed features of the Solar Tracking System. The third and fourth sections present the software, test and result of the overall system. Conclusion is mentioned in the fifth section.

\section{SYSTEM DESCRIPTION}

The propose system is the Arduino based variable and compactable system with a single axis solar tracking system. The Arduino gets the data from the two LDR sensors to rotate the solar panel to the lighting place by using the motor driver and the stepper motor. The voltage divider method is used as the voltage sensor. The battery is used to store the energy from the solar panel and applied to the loads. The block diagram of single axis solar tracking system is shown in Figure 1.

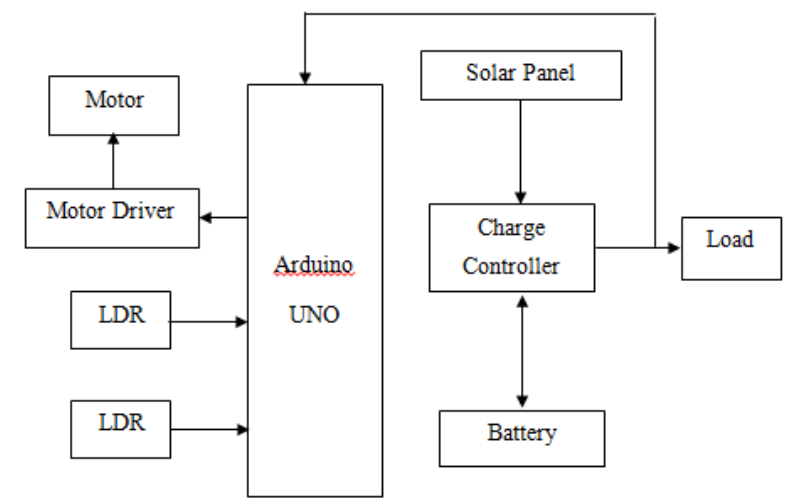

Figure 1. Block diagram of Solar Tracking System

\subsection{Microcontroller}

The Arduino Uno is a microcontroller board based on the ATmega328 (datasheet). It has 14 digital input/output pins (of which 6 can be used as PWM outputs), 6 analog inputs, a 16 $\mathrm{MHz}$ ceramic resonator, a USB connection, a power jack, an ICSP header, and a reset button. It contains everything needed to support the microcontroller; simply connect it to a computer with a USB cable or power it with an AC-to-DC adapter or battery to get started. The Uno differs from all preceding boards in that it does not use the FTDI USB-toserial driver chip. Instead, it features the Atmega16U2 (Atmega8U2 up to version R2) programmed as a USB-toserial converter.

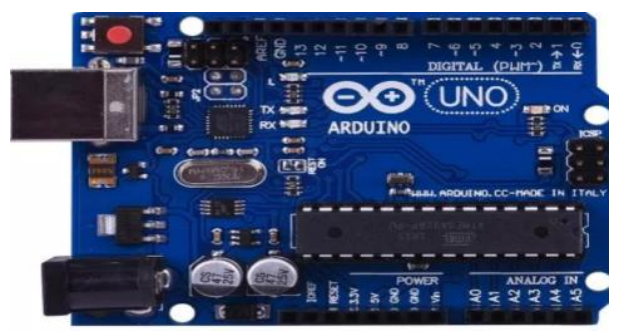

Figure 2. Arduino Uno 


\subsection{Solar Cell}

The photovoltaic cell is the basic building block of a photovoltaic system. The individual cells can vary from 0.5 inches to 4 inches across. One cell can however produce only 1 or 2 watts that is not enough for most appliances. Performance of a photovoltaic array depends on sunlight. Climatic conditions like clouds and fog significantly affect the amount of solar energy that is received by the array and therefore its performance. Most of the PV modules are between 10 and 20 percent efficient.

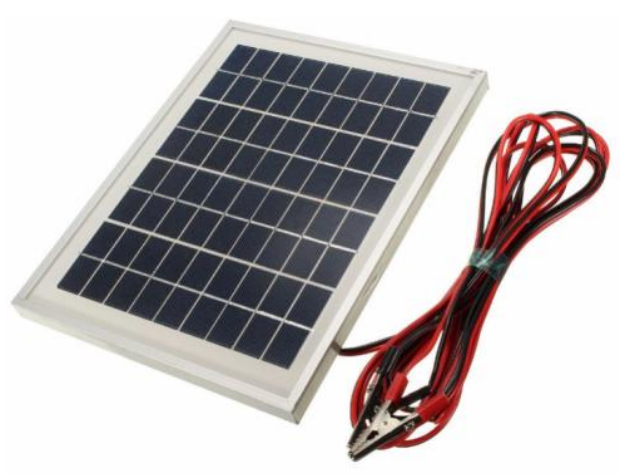

Figure 3. Solar cell

\subsection{Stepper Motor}

There are many types of motors AC; DC; Servo and Stepper motors. Stepper motors are DC motors that move in discrete steps. They have multiple coils that are organized in groups called "phases". By energizing each phase in sequence, the motor will rotate one step at a time. With a computer controlled stepping can achieve very precise positioning and/or speed control. For this reason, stepper motors are the motor of choice for many precision motion control applications.

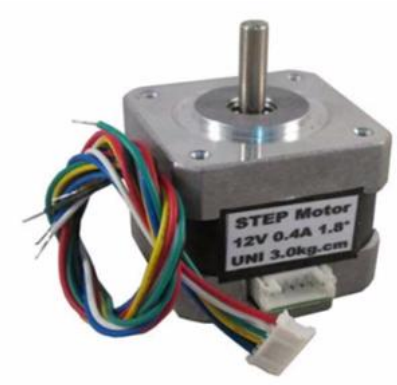

Figure 4. Stepper motor

\subsection{Motor Driver}

This is a professional two-phase stepper motor driver. It supports speed and direction control. Driver's micro step and output current can be set with 6 DIP switch. There are 7 kinds of micro steps $(1,2$ / A, 2 / B, 4, 8, 16, 32) and 8 kinds of current control $(0.5 \mathrm{~A}, 1 \mathrm{~A}, 1.5 \mathrm{~A}, 2 \mathrm{~A}, 2.5 \mathrm{~A}, 2.8 \mathrm{~A}, 3.0 \mathrm{~A}, 3.5 \mathrm{~A})$ in all. And all signal terminals adopt high-speed optocoupler isolation, enhancing its anti-high-frequency interference ability.

The features of stepper motor driver are:
- Support 8 kinds of current control

- Support 7 kinds of micro steps adjustable

- The interfaces adopt high-speed optocoupler isolation

- Automatic semi-flow to reduce heat

- Large area heat sink

- Input anti-reverse protection

- Overheat, over current and short circuit protection

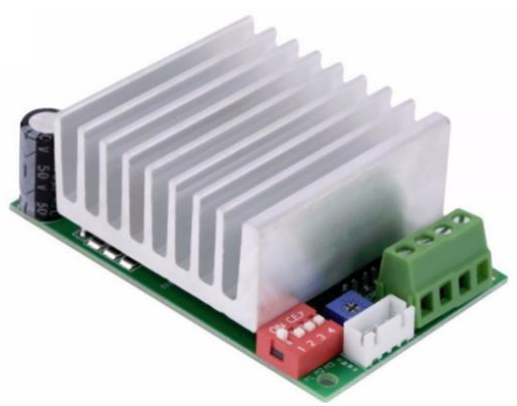

Figure 5. TB-6600 stepper motor driver

\subsection{LDR Sensors}

The lighting sensor is composed the fixed resistor and the light dependent resistor (LDR). Supply voltage is $5 \mathrm{~V}$, and the voltage of LDR cannot be connected directly to the controller. So, voltage divider method is applied to read the voltage of LDR. The value of voltage difference between two LDRs is compared to the sensitivity, because the motor cannot be rotated every time on the whole day. The solar tracking system is designed to rotate $\mathrm{CW}$ or $\mathrm{CCW}$ directions according to the greater level of voltage when the voltages difference of two LDRs. When the voltage difference is greater than or not the sensitivity, the motor rotates to its respective direction.

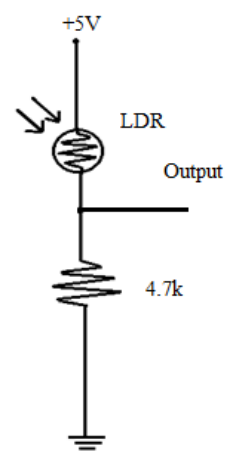

Figure 6. LDR sensor circuit

In the above circuit, a complementary resistor with a value of $4.7 \mathrm{k} \Omega$ is used to get the desired output voltage signals. Regulated voltage supply is $5 \mathrm{~V}$.

The output voltages are calculated by using the following equation;

For maximum, let $\mathrm{R}_{1}=\mathrm{R}_{\mathrm{LDR}(\max )}=1 \mathrm{M} \Omega$,

Assume, $\mathrm{R}_{2}=4.7 \mathrm{k} \Omega$, using voltage divider,

$\mathrm{V}_{\text {out }}=\left[\mathrm{R}_{2} /\left(\mathrm{R}_{\mathrm{LDR}}+\mathrm{R}_{2}\right)\right] \times \mathrm{V}_{\text {cc }}$ and the output voltage is $0.02 \mathrm{~V}$.

For midpoint, let $\mathrm{R}_{1}=\mathrm{R}_{\mathrm{LDR} \text { (mid) }}=1 \mathrm{k} \Omega$,

Assume $R_{2}=4.7 \mathrm{k} \Omega$, the output voltage is $4.12 \mathrm{~V}$. 


\subsection{Overall Circuit Diagram}

The overall circuit diagram is illustrated in Figure 7. There are three parts in the control systems; LDR sensor, microcontroller and stepper motor. The LDR sense the sunlight and send the data to the microcontroller. The microcontroller control TB-6600 motor drivers to drive the stepper motor change direction depend upon the signal on LDR sensors. The solar panel tracks the sunlight to have the maximum power. The charge controller is used to control the voltage charging to the battery.

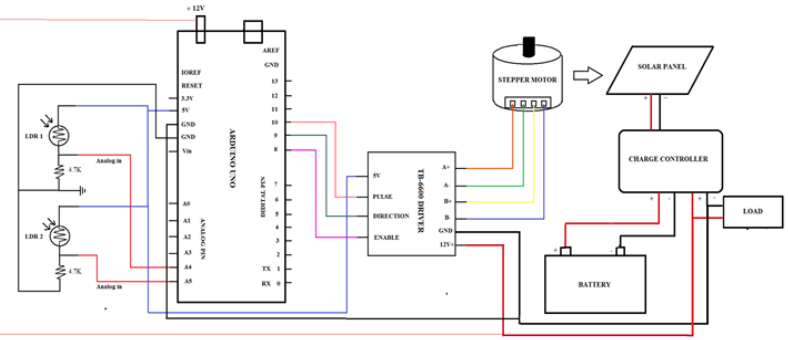

Figure 7. Overall Circuit of Single Axis Solar Tracking System

\section{SOFTWARE IMPLEMENTATION}

\subsection{Program Flowchart of the System}

Firstly the header files, the variable, input and output pins are considered to initialize. Then the dada from LDRs are read. The difference between the two LDR and sensitivity are compared. If the measured difference between the set of sensors is greater than the sensitivity value, the direction pin on Arduino is HIGH. The motor rotates CW direction. Or the direction pin on Arduino is LOW and the motor rotates CCW direction.

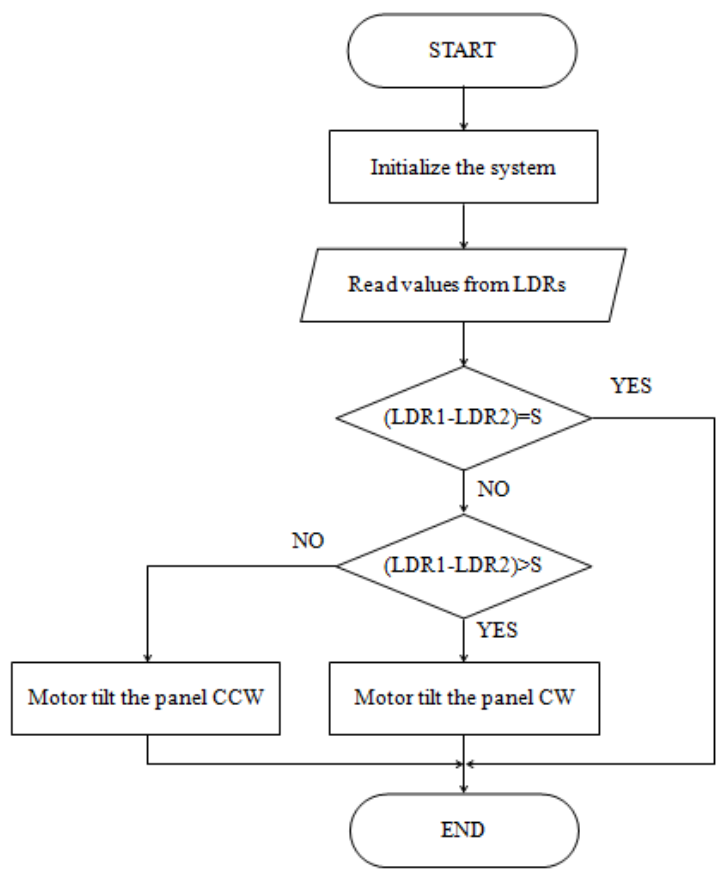

Figure 8. Program flowchart of the solar tracking

\subsection{Simulation and Compiling}

To simulate and compile the whole system, Arduino IDE software is established. Figure 9. shows the test result of compiled code is succeeded.

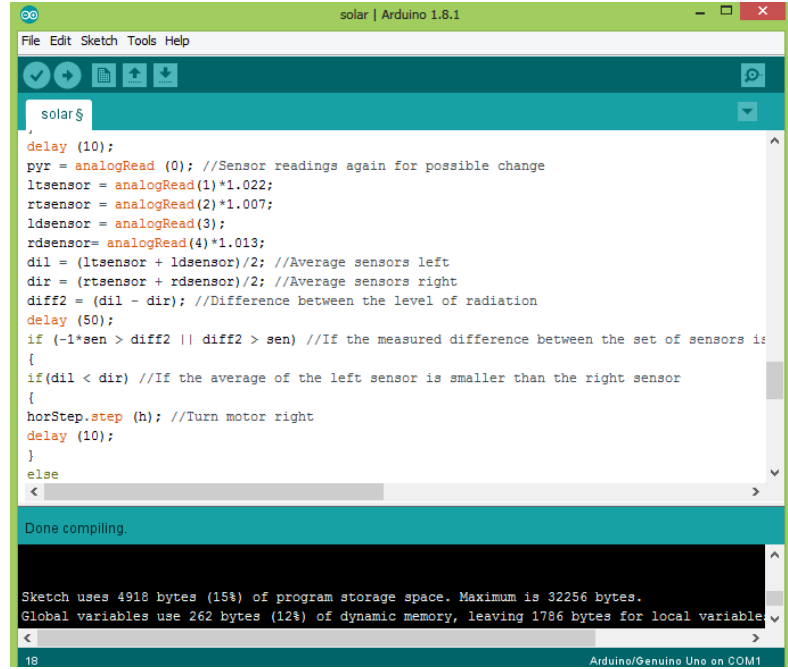

Figure 9. Compilation result of the program

\section{TEST AND RESULT}

Figure 10. shows the testing of microcontroller, BT-6600 motor driver and stepper motor. Implementation of the system is partially developed without solar panel.

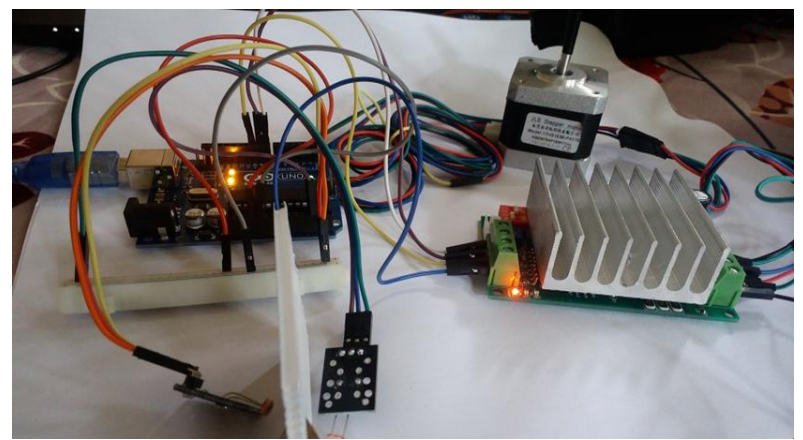

Figure 10. Testing of microcontroller, BT-6600 motor driver and stepper motor

Figure 11. shows implementation of the system is developed with solar panel.

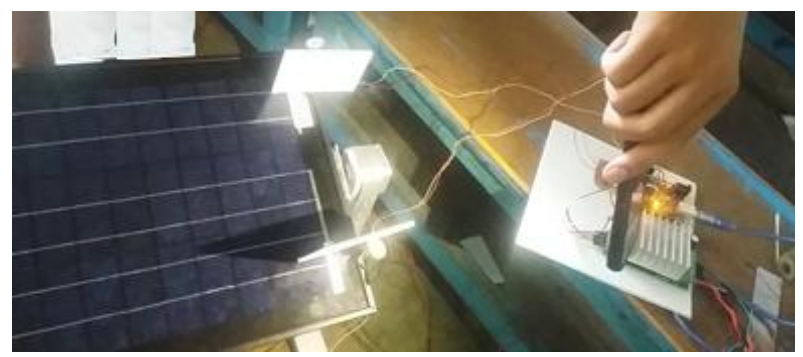

Figure 11. Testing of the whole system

\subsection{Data Analysis}

The data from the two LDRs are converted to analogue voltages and compared to hour by hour. But there are not much changed in the day. If here is no light, the system is switched off to reduce power consumption. Table 1 . shows the comparison of the voltages on cloudy day.

Table 1. The comparison of the voltages on cloudy day

\begin{tabular}{|c|c|c|}
\hline Time & LDR 1 Volt & LDR 2 Volt \\
\hline 8:00 Am & 3.76 & 3.88 \\
\hline
\end{tabular}




\begin{tabular}{|c|c|c|}
\hline 9:00 Am & 3.96 & 4.22 \\
\hline 10:00 Am & 4.24 & 4.52 \\
\hline $11: 00 \mathrm{Am}$ & 4.48 & 4.72 \\
\hline $12: 00 \mathrm{Am}$ & 4.78 & 4.75 \\
\hline $1: 00 \mathrm{Pm}$ & 4.69 & 4.64 \\
\hline $2: 00 \mathrm{Pm}$ & 4.60 & 4.65 \\
\hline $3: 00 \mathrm{Pm}$ & 4.32 & 4.36 \\
\hline
\end{tabular}

To illustrate the voltages from the two LDRs, line chart is used as shown in Figure.

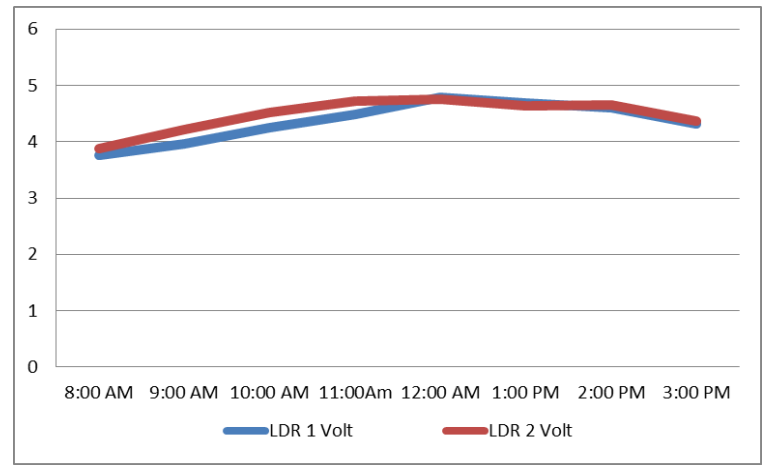

Figure 12. Line chart for the data from two LDRs in cloudy day

Table 2. shows the comparison of the voltages on sunny day.

Table 2. The comparison of the voltages on sunny day

\begin{tabular}{|c|c|c|}
\hline Time & LDR1 & LDR2 \\
\hline 8:00 Am & 1.55 & 1.61 \\
\hline 9:00 Am & 1.82 & 1.85 \\
\hline 10:00 Am & 2.40 & 2.52 \\
\hline 11:00 Am & 2.65 & 2.71 \\
\hline 12:00 Am & 2.89 & 3.08 \\
\hline 1:00 Pm & 3.02 & 3.14 \\
\hline 2:00 Pm & 2.75 & 2.86 \\
\hline 3:00 Pm & 2.42 & 2.54 \\
\hline
\end{tabular}

To illustrate the voltages from the two LDRs, line chart is used as shown in Figure 13.

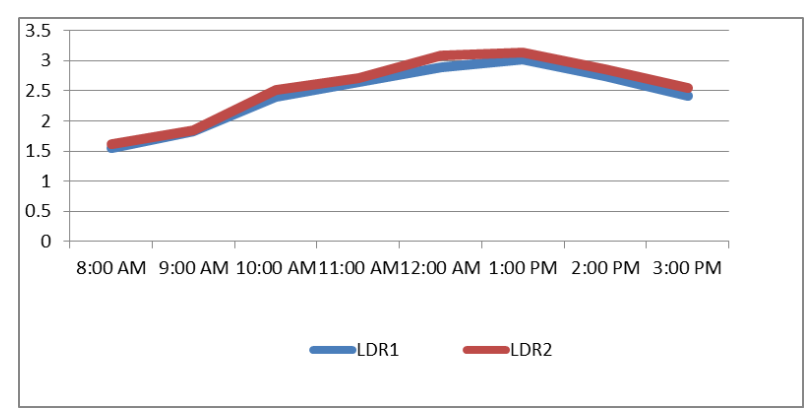

Figure 13. Line chart for the data from two LDRs in sunny day
From the data, it can be seen that the voltage from cloudy day is less as twice as the sunny day. But voltage difference of cloudy day is greater than the sunny day. So the motion of solar panel is infrequently changed in sunny day.

\section{CONCLUSION}

An Arduino based single axis solar tracking system was designed and constructed in the current work. LDR light sensors were used to sense the light intensity of the sun with the help of the photovoltaic cells. The stepper motor had enough torque to drive the panel. Stepper motors are noise free and are affordable, making them the best choice for the project.

The compact, cost effective and reliability of this solar tracker is intended to suitable for the rural usage. The purpose of renewable energy from this work offered advance in idea to help the people. This system can be designed to provide electricity to the entire home by changing solar panel, using more efficient sensors and designing the charge controller. Instead of single axis tracker, dual axis tracker are also performed and compared to the single axis. Solar car and solar motorbike can be developed for pollution problems without using resource from the world.

\section{ACKNOWLEDGMENTS}

The author would like to thank to her teachers, family and partners who have contributed towards development of this work.

\section{REFERENCES}

[1] Anne Rosenblatt, Nicole Aaron. 2014. "SOLAR TRACKING SYSTEM', Project Report for Swarthmore College Engineering Department.

[2] Oloka Reagan Otieno, 2009. "SOLAR TRACKER FOR SOLAR PANEL", University Of Nairobi.

[3] Thomas L. Floyd.2007. "Electronic Fundamentals: Circuit, Devices and Application".

[4] S. Armstrong, W.G Hurley. 2009. "Investigating the Effectiveness of Maximum Power Point Tracking for a Solar System", The IEEE Conference on Power Electronics Specialists.

[5] Damm,J. 1990. "An active solar tracking system", Home Brew Magazine, Issue \# 17.

[6] Simon Monk. 2011. " Programming Arduino: Getting Started with Sketches".

[7] J.A. Beltran, J.L.S. Gonalez Rubio, C.D. Garcia Beltran. 2007. " Design, Manufacturing and Performance Test of a Solar Tracker Made by Embedded Control, CERMA, Mexico

[8] David Cooke. 2011. " Single vs. Dual Axis Solar Tracking", Alternate Energy eMagazine.

[9] Kumar Lokhande. 2014. "AUTOMATIC SOLAR TRACKING SYSTEM", International Journal Of Core Engineering \& Management (IJCEM), Volume 1, Issue 7. 